\title{
COLABORACIÓN Y RESISTENCIA ENTRE SANGRE Y LECHE EN CUBA Y PUERTO RICO: LAS NODRIZAS EN CECILIA VALDÉS DE CIRILO VILLAVERDE Y VECINDARIOS EXCÉNTRICOS DE ROSARIO FERRÉ
}

\author{
POR \\ IvetTe GuZMÁn-ZavalA \\ Lebanon Valley College
}

En la novela antiesclavista cubana de Cirilo Villaverde Cecilia Valdés (1882) y en Vecindarios Excéntricos (1998) de la puertorriqueña Rosario Ferré hay una nodriza bajo la supervisión de mujeres blancas de clase privilegiada. En este ensayo, el personaje de María de Regla de la novela cubana funciona como punto de partida para elaborar una comparación entre ambas nodrizas. Las transformaciones que se producen a través de estos personajes en distintos momentos históricos revelan cambios en las relaciones interraciales y de género y amplían las significaciones que puede asumir la leche, mientras mantienen limitaciones producto de la herencia histórica caribeña. ${ }^{1}$ Aún con el distanciamiento de más de un siglo entre ambas publicaciones, se verá como la leche puede funcionar como un vehículo para que el sujeto femenino subalterno tenga acceso (parcial) al espacio privilegiado de la familia y a la voz narrativa de la hija blanca. Sin embargo, las conexiones establecidas por la leche de una nodriza negra permanecen en tensión constante ya que amenazan el lazo biológico o de sangre que consolida el privilegio de las mujeres blancas.

El análisis de las relaciones con las nodrizas muestra los intercambios culturales que se han dado históricamente en el Caribe hispano, trasfondo de interacciones y mezclas de varias culturas. Los contactos con una madre no-biológica revelan además modos de pensamiento y comportamientos sociales pertinentes a las vidas de mujeres y madres caribeñas. ${ }^{2}$ En los textos aquí estudiados ni María de Regla ni Miña son protagonistas.

1 George B. Handley (2000) distingue entre la literatura antiesclavista como Cecilia Valdés y la postesclavista en el caso de Vecindarios Excéntricos. La primera intenta moralizar y representar lo inhumano de la esclavitud y la humanidad del esclavo, con la esperanza de un futuro en que puedan legitimizar y reconstruir su familia y comunidad. La literatura postesclavista utiliza este legado y representa la genealogía y la historia familiar apuntando hacia los contactos de raza y clase que han existido pero han permanecido ocultos. Para este análisis ver Postslavery Literatures in the Americas: Family Portraits in Black and White (2000).

2 Valerie Fildes (1988) identifica tres grupos étnicos que funcionaron como nodrizas durante la época colonial: las indígenas de América, las esclavas africanas y también algunas mujeres blancas europeas. 
Por eso una lectura centrada en ellas requiere, como señalan Andersen y Collins (2007) el movilizar la perspectiva del lector/a para incluir aquellos que tradicionalmente han sido ignorados.

La metáfora de la familia como símbolo de la nación es un aspecto central del análisis que ilumina este estudio. Esta metáfora ha sido ampliamente estudiada en la literatura del Caribe hispano e informa la mayoría de los estudios sobre estas novelas. ${ }^{3} \mathrm{Al}$ imaginar la familia como símbolo de la nación con el factor de una madre no-biológica, se reorganiza su estructura para acomodar al sujeto subalterno.

Ivonne Knibiehler señala que "la leche humana no es solamente una secreción biológica: también "segrega" representaciones imaginarias y relaciones sociales" $(95){ }^{4}$

La "madre patria" europea manejaba las regulaciones acerca de la lactancia en "América" con diferencias de acuerdo al espacio geográfico donde se desempeñaban estas labores. Hoy en día carecemos de investigación abundante sobre las distintas maneras que se ejerce la maternidad en el Caribe hispano.

Tanto Gladys Feijoo como María Teresa Aredo abordan el tema de las tensiones que surgen entre los personajes femeninos en Cecilia Valdés. Para más información sobre este tema ver sus respectivos artículos.

3 La equiparación de familia y nación está el trasfondo de los análisis de Cecilia Valdés y de Vecindarios excéntricos que incluyo en este estudio y aparece también en muchos otros textos caribeños. En el contexto puertorriqueño por ejemplo, María Caballero la analiza en la producción literaria de varios autores del siglo xx como Edgardo Rodríguez Juliá, Luis Rafael Sánchez y Rosario Ferré, entre otros. Juan G. Gelpí (1993) se basa en lo que llama "una metáfora privilegiada: la equiparación de Puerto Rico con una gran familia" (54) para su análisis en Literatura y paternalismo en Puerto Rico. Esta metáfora también informa el análisis de Yolanda Martínez-San Miguel en Puerto Rican Jam (1997) enfocando en autores como Zeno Gandia, Antonio S. Pedrerira y otros. Para un análisis de la nación como una familia en la producción literaria de la isla y su diáspora ver el texto de Marisel C. Moreno (2012).

4 La leche no es la única que engendra relaciones significativas en la literatura femenina contemporánea donde las relaciones entre madres, hijas, abuelas y niñeras es un tema frecuente. Las puertorriqueñas Magali Garcia Ramis, Mayra Santos Febres, Rosario Ferré y Olga Nolla exploran estos temas en sus narrativas, al igual que Nicholasa Mohr, Esmeralda Santiago y Judith Ortiz Cofer desde los EEUU. Las ensayistas Sofía Irene Cardona, Mari Mari Narváez y Vanessa Vilches Norat en Fuera del quicio (2007) incluyen también meditaciones sobre la experiencia de la maternidad. Las conexiones que resultan del contacto corporal y a través de la leche son elementos importantes también en textos de autoras africano-americanas y caribeñas. En The Daughter's Return por ejemplo, Caroline Rody menciona "the plot of cross-cultural connection" (125). Según esta idea "fictional daughters of the Caribbean find inspiration, knowledge, and love in transhistorical and transcultural meetings with other women" (125). La maternidad biológica y no-biológica es explorada también tanto en la literatura caribeña como en textos de identidades diapóricas en los EEUU. Ruth Behar describe la relación con su nana negra en Cuba identificando la tendencia de damas de clase privilegiada de reproducir patrones patriarcales de discriminación en su trato con las sirvientas o niñeras aún a pesar de la relación afectiva que puede existir entre ambas. Por otro lado, la estadounidense Adrienne Rich utiliza la relación con su nana (anónima) negra para cuestionar la definición de la maternidad institucionalizada. La maternidad institucionalizada -la cual Rich distingue de la experiencia de la maternidad- privilegia las conexiones que se crean a través del aspecto biológico del embarazo y el parto. Sin embargo, el lazo que se forma a través de la leche funciona para identificar nuevas definiciones de la maternidad cuando esta lazo es reconocido por

Revista Iberoamericana, Vol. LXXXI, Núm. 250, Enero-Marzo 2015, 217-232 ISSN 0034-9631 (Impreso)

ISSN 2154-4794 (Electrónico) 
Es decir, que además del valor alimenticio, en un texto literario la leche provoca otras significaciones y crea relaciones personales. Estas relaciones se establecen a través del contacto corporal, el cual requiere la separación forzada de los hijos biológicos en el caso de una nodriza. Como se verá, durante estos procesos surgen ansiedades y ambigüedades ya que los lazos que generan estos contactos cruzan barreras sociales de clase y raza. De hecho, aún después de terminada la lactancia, en ambas novelas las nodrizas intentan mantener contacto con personajes femeninos de la clase alta, causando tensiones. Ellas no sólo asumen responsabilidades maternas sino que crean lazos afectivos y proveen un modelo alternativo de mujer que la madre biológica desaprueba. Desde su posición de madre alternativa o secundaria, la nodriza aporta una perspectiva distinta de la acción narrativa y/o de la historia nacional.

Cecilia Valdés comienza con una escena reveladora de las ansiedades que generan los contactos corporales que cruzan los límites de raza y clase en una sociedad esclavista. Una mulata ha sido separada abruptamente de su hija recién nacida, Cecilia. Este hecho es parte del secreto que informa gran parte de la acción de la novela. Don Cándido, el padre de Cecilia, es un hombre blanco de clase alta quien dictamina que será "María de Regla, mi negra" (16) quien estará encargada de alimentar la bebé ya que tenía leche "buena y abundante" que "debe aprovecharse" (397). El hombre blanco de clase alta decide quién alimentará a los de su clase y -en el caso de Cecilia-a los hijos "ilegítimos" de la misma demostrando que los conceptos de clase y género están íntimamente ligados en una sociedad esclavista y patriarcal.

María de Regla no sólo provee sustento a través de la leche sino que además mantiene el secreto de adulterio de don Cándido, quien está casado con doña Rosa. El mantenimiento del secreto de la infidelidad y mezcla racial además del alimento y el cuido son esenciales para el soporte de la clase alta. La mezcla de raza y clase -que encarna Cecilia-debe mantenerse escondida y al margen de la formación de una identidad nacional que desea identificarse como blanca y excluye a los ubicados en una categoría más baja. Por eso, Amy Robinson (2006) señala que Cecilia Valdés logra desenmascarar los conflictos de la época aunque no representa la conciliación de sus fragmentos.

El trabajo de la clase baja y los esclavos sustentaba la clase privilegiada. La tarea de la nodriza ejemplifica esta labor desde una perspectiva de género. Los servicios de María de Regla habían sido originalmente dirigidos hacia Adela, la hija de don Cándido y doña Rosa, quien no lactó “por no sentirse ella en condiciones para desempeñar por

la hija:" My Black mother was "mine" only for four years, during which she fed me, dressed me, played with me, watched over me, sang to me, cared for me tenderly and intimately. "Childless" herself, she was a mother (Rich 254). Rich señala que algunas hijas tienen la opción de identificarse con la madre biológica o con la nana, una artista o una maestra y que como consecuencia "many of the great mothers have not been biological" (252).

Revista Iberoamericana, Vol. LXXXI, Núm. 250, Enero-Marzo 2015, 217-232 ISSN 0034-9631 (Impreso)

ISSN 2154-4794 (Electrónico) 
entonces aquél, el más dulce de los deberes de madre" (Villaverde 213). Esta decisión es un privilegio más de la mujer de clase alta. La "señora" puede tomar decisiones también sobre el cuerpo de la esclava, ya que los hijos y la leche de ésta pertenecían al amo o ama, quien incluso recibe un salario por el alquiler de la nodriza.

Vera M. Kutzinski (1993) señala en el contexto cubano que la mujer que provee un servicio es una imagen familiar en la imaginación colonial, que a su vez mantiene marcadas limitaciones sobre ella. La raíz de estos controles radica en el miedo a las revueltas de esclavos en el siglo XIx. En la novela de Villaverde las prohibiciones de la esclava mantienen las divisiones de raza y clase mientras revelan el miedo y ansiedad: "Prohibiósele explícitamente a María de Regla el dividir sus caricias y el tesoro de su seno entre las dos niñas, siquera el tomarla juntas en brazos" (213). Sin embargo, y a escondidas, María lactaba a ambas, porque "aunque era esclava" [...] "era madre" (213). ${ }^{5}$ El resultado es que "como en realidad mamaran una misma leche, no obstante su opuesta condición y raza, se amaron con amor de hermanas" (215). Esta conexión que se da a través de la leche amenaza con sustituir el lazo de la sangre y borrar las diferencias imprescindibles para quienes ocupaban el poder. Sin embargo, las resultantes relaciones siguen siendo ambigüas y problemáticas.

En Cecilia Valdés las escisiones entre una mujer blanca y la esclava son imposibles de superar a menos que se establezca una relación afectiva a través de la leche. Doña Rosa no posee este vínculo con María de Regla y descubre el secreto de la nodriza cuando la halla con las dos niñas, la blanca Adela y la negra Dolores (hija de María). El castigo es el destierro y la separación definitiva de ambas niñas y de su propio marido. Además la esclava sufre un descenso en su posición ya marginal con "el cambio de ocupación de ama de leche en la ciudad por el de enfermera en el campo" (Villaverde 215). Cuando más adelante se le ocupa para alimentar también a Cecilia crecen el odio, los celos y la desconfianza de doña Rosa, quien desconoce quién es el padre de esa niña. De esta manera Adela, Dolores y Cecilia terminan siendo hermanas de leche, formando un lazo que no es reconocido en la sociedad en que viven.

A pesar de que Adela y Dolores mantienen una relación afectiva, se mantienen las desigualdades entre ellas ya que la sociedad esclavista no permite la eliminación de las divisiones a las que ellas han sido expuestas desde su niñez. El texto señala que se amaban, pero la blanca Adela va a la escuela mientras que Dolores se mantiene en una posición de servicio y "les llevaba los libros junto con la fruta y el refresco a medio día" (215). Dolores reproduce algunas de las labores relacionadas con la maternidad, ya que "las vestía, las peinaba, les lavaba los pies a la hora de acostarse" (215) pero dormía "en el duro suelo al lado de la cama de Adela" o "en el cuarto inmediato sobre

Para un análisis sobre la representación de la esclava como madre en la novela de Villaverde ver los artículos de María Teresa Aedo, Lorna Williams y Gladys Feijoo.

Revista Iberoamericana, Vol. LXXXI, Núm. 250, Enero-Marzo 2015, 217-232 ISSN 0034-9631 (Impreso)

ISSN 2154-4794 (Electrónico) 
rígida tarima a la vista de otra criada" (Villaverde 215). Sin embargo, la relación de hermanas de leche y la proximidad física le permite a Dolores contarle a Adela la historia del sacrificio y sufrimiento de su madre esclava incluyendo "el maltrato que le daban" y "la triste historia de los trabajos y padecimientos de María de Regla en el ingenio" (216). Dolores quiere que perdonen a su madre y le insiste a Adela para que hable con doña Rosa del asunto. Así la hija esclava inserta la narrativa de su madre a través de la "hermana" blanca, quien a su vez le insiste a doña Rosa la eliminación del castigo. La combinación del lazo biológico (representado en Dolores) y el de la leche materializan la defensa de Adela ante doña Rosa a favor de María de Regla. Adela le ruega a su madre que perdone a María y más tarde escucha el secreto de los labios de la nodriza. El contacto y la leche permiten que la esclava cuente su historia -aunque a una audiencia restringida- para tener influencia en la clase alta. ${ }^{6}$

La novela de Rosario Ferré Vecindarios excéntricos (1998) cuenta la saga de una familia puertorriqueña en el siglo xx narrada por Elvira, la hija de la protagonista. La posibilidad de tener una narradora femenina es evidencia de una mayor libertad de expresión lograda en el siglo xx por algunas mujeres caribeñas. Elvira centra su atención en la historia personal de su madre, Clarissa, quien es la hija primogénita de una familia privilegiada. Al poco tiempo de nacida Clarissa desarrolla fiebre reumática por una picada de mosquito y su sobrevivencia depende de su alimentación. Sin embargo su madre biológica, Valeria, no quiere lactarla porque "sus nervios estaban desechos y no podía ocuparse de ella" (116). Además "los pezones se oscurecerían como los de las mulatas, lo que le daba terror" (Ferré 117). La diferencia entre la clase trabajadora y relacionada con la negritud a la que pertenece Miña y la de Valeria, relacionada con la blancura y el poder, se transcribe al cuerpo y se manifiesta en ese miedo de parecerse a la otra. Además, según Elvira las mujeres de clase alta tenían una agenda bien definida y una constitución física supuestamente más débil. ${ }^{7}$

6 Para un análisis detallado de las relaciones interraciales dentro de la misma familia en Cecilia Valdés, ver el artículo de María Teresa Aedo. La novela muestra cómo en una sociedad esclavista y patriarcal los esclavos internalizan la discriminación racial y de género. María de Regla favorece a su hijo Tirso sobre Dolores ya que tenía el color de piel más claro. La discriminación por género en sus propios hijos es la única característica que comparten la esclava en Cecilia Valdés y la mujer blanca de clase alta de Vecindarios Excéntricos. Mientras Valeria favorece al hijo varón, Leonardo, María de Regla reconoce aún desde su posición de esclava la posibilidad de ganar algún privilegio social a través de Tirso, quien era hijo biológico blanco y como tal "mejoraba la condición". Su hija Dolores, por otro lado, "perpetuaba el odioso color" (216). Ambas mujeres, en distintas épocas históricas, coinciden en su intento de mantener esa parte del sistema patriarcal.

7 Eileen J. Suárez Findlay (1999) analiza las diferencias que históricamente han separado las mujeres puertorriqueñas debido a clase y raza en Imposing Decency: The Politics of Sexuality and Race in Puerto Rico, 1870-1920. El concepto de la moral con la cual se podía medir el honor y respectabilidad femenina era uno variable de acuerdo a la clase a la que pertenecía la mujer. Estas ideas impidieron que hubiese una cohesión y un movimiento feminista sólido que sobrepasara diferencias de clase hasta más tarde en el siglo $\mathrm{xx}$.

Revista Iberoamericana, Vol. LXXXI, Núm. 250, Enero-Marzo 2015, 217-232 ISSN 0034-9631 (Impreso)

ISSN 2154-4794 (Electrónico) 
En aquella época las señoras puertorriqueñas no amamantaban a sus hijos.

Estaban elegantemente vestidas a toda hora y acompañaban a sus maridos a los convites sociales. Sus deberes se limitaban a mecerlos en la cuna y a arrullarlos con tonadillas de antaño. Abuela Valeria estaba muy orgullosa de sus pechos, que eran blancos como el alabastro y del tamaño perfecto, con pezones tan delicados como botones de rosa (117).

Es decir, que la lactancia no era una labor propia de la clase social de Valeria porque limitaba sus deberes de mujer y esposa y era una labor dura, mejor asumida por un cuerpo robusto como se suponía que era el de una esclava o mujer 'de color'.

Ann Stoler describe las motivaciones en los deseos de controlar los sujetos subalternos por parte de la clase alta en el espacio del hogar. Su estudio analiza las relaciones domésticas interraciales y su efecto en los niños en un contexto colonial. Según Stoler, los sirvientes y niñeras representan un peligro por su potencial de ejercer influencia o cambio en los menores y por consecuencia, en el futuro de la nación. La leche de la nodriza podía transportar características personales e ideas que se infiltrarían en la raza blanca y en la clase privilegiada: "A baby was thought to absorb the 'personality traits' of his nurse when he drank her "whitened blood" ["Se pensaba que un bebe absorbía los 'rasgos de la personalidad' de su nodriza cuando tomaba la 'sangre blanca' de ella"] (Stoler 145; traducción del editor). La amenaza del contagio se extiende a los cuidados y atenciones que, si se exageraran, podrían también dañar a los niños. Se concebía entonces un tipo de contagio no sólo físico sino también afectivo (Stoler 112).

Las primeras descripciones de Miña Besosa en Vecindarios excéntricos destacan la diferencia de raza, clase y género: "Miña era mitad india taína y mitad negra jelofe, y su familia era muy pobre" (Ferré 116). Aunque la novela toma lugar en el siglo xx se retrata nuevamente una realidad que ha existido desde mucho antes no sólo en el Caribe sino también en América Latina, en donde mujeres pobres han sostenido a los hijos de la clase privilegiada con algún tipo de servicio.

Los taínos habitaban la isla antes de comenzar la colonización española en el siglo xv. Esta población disminuyó rápidamente debido a nuevas enfermedades y al trabajo brutal al que fueron obligados. A partir del siglo Xvi se les unieron como fuerza trabajadora los esclavos africanos como mano de obra en el cultivo de la caña de azúcar y el café, así como en el trabajo doméstico. Miña representa la combinación de ambos grupos subalternos evidenciando la mezcla racial que forma parte del mito fundacional de la identidad en Puerto Rico. Miña no es ni blanca ni negra y puede ser mejor descrita como "trigueña" o "morenita" usando dos de las categorías raciales que identifica el historiador Jorge Duany $(236) .{ }^{8}$ A pesar de que existe una considerable

8 Jorge Duany (2002) explica que actualmente existe una amplia variedad de colores de piel y fenotipos en Puerto Rico, donde se utilizan al menos diecinueve diferentes categorías raciales. Miña representa una o dos de estas categorías. Para mas información, y un desglose de estos términos ver su texto.

Revista Iberoamericana, Vol. LXXXI, Núm. 250, Enero-Marzo 2015, 217-232 ISSN 0034-9631 (Impreso) 
aceptación social y bastante experiencia de mezcla racial en Puerto Rico, Valeria, la mamá de Clarissa, no lacta porque teme los cambios que supone pueden ocurrir en su propio cuerpo como consecuencia. Julio Ramos identifica este miedo al contacto racial en los discursos nacionales basados en pureza y contagio señalando que la mezcla racial podría destruir la blancura asociada con el poder. Las mujeres como Valeria quieren la leche de mujeres como Miña porque se considera saludable y porque además sustenta su privilegiada posición social. Así se depende de la nodriza pero se le mantiene a distancia, bajo espectativas estrictas de comportamiento y medidas de supervisión. ${ }^{9}$

Al igual que en Cecilia Valdés, en Vecindarios Excéntricos es el padre quien escoge a la nodriza de sus hijos. Álvaro la elige al verla embarazada por quinta vez ya que parecía ser conocimiento general que "sus cuatro hijos eran los más saludables de Camarones, gracias a su leche abundante" (116). Álvaro visualiza la posibilidad de éxito en el trabajo de nodriza a través de una "lectura" sexualizada de su cuerpo: "La ropa mojada se adhería a su cuerpo de forma reveladora. Parecía llevar una berenjena gigante sobre la barriga y dos más pequeñas adheridas al pecho" (116). Las redondeces y la comparación con las frutas alude al alimento, haciéndola doblemente atractiva y llena de posibilidades ante los ojos del patriarca.

El contacto del cuerpo taíno y africano de Miña con la niña blanca forma una imagen que alude y simultáneamente cuestiona la manera en que la identidad racial ha sido representada en Puerto Rico. El antropólogo puertorriqueño Ricardo Alegría identificó tres raíces raciales que aparecen representadas como figuras masculinas en el emblema del Instituto de Cultura Puertorriqueña excluyendo al cuerpo femenino. ${ }^{10}$ Jorge Duany lo describe como sigue:

The seal represents a well-dressed Spaniard in the center with a grammar book in his hand and three Catholic crosses in the background; to his right stands a seminude Taíno with a cemí and a corn plant, to his left, a topless African holds a machete and a drum, with a vejigante mask lying on his feet and a sugarcane plant on one side.

[El sello representa a un español en el centro, bien vestido con un libro de gramática en su mano y tres cruces católicas en el fondo, a su derecha se encuentra un Taíno semidesnudo con un cemí y una planta de maíz; a su izquierda, un africano sin sostén sosteniendo un machete y un tambor, con una máscara del vejigante a sus pies y una planta de caña a su lado] (Duany 277; traducción del editor).

9 Este aspecto sobre las nodrizas en el Caribe y en Sur América en la literatura ha sido estudiado ampliamente por Julio Ramos y Jossiana Arroyo. Estoy citando del libro de Ramos Paradojas de la letra (1996) y de su artículo inédito, Wet nurses and Contact con permiso del autor.

10 El Instituto de Cultura Puertorriqueña fue creado en 1955 y Ricardo Alegría fue su primer director. Alegría fue un prominente antropólogo puertorriqueño hasta su muerte en julio del 2011.

Revista Iberoamericana, Vol. LXXXI, Núm. 250, Enero-Marzo 2015, 217-232 ISSN 0034-9631 (Impreso) ISSN 2154-4794 (Electrónico) 
En el modelo femenino de la novela de Ferré estos cuerpos tienen contacto corporal y es la bebé blanca quien necesita las otras razas para alimentación. Ya que Miña incorpora a taínos y africanos, hay dos cuerpos en vez de tres, aludiendo a las relaciones entre madres e hijas que fomentarían esta conexión. Finalmente, la conexión se da por la leche, en lugar del lazo sanguíneo que privilegia la herencia española, ofreciendo una alternativa al modelo tradicional.

Miña no sólo amamanta a Clarissa, sino también a sus cuatro hermanas y hermano. De acuerdo a Álvaro, así serían "hermanos de leche" y se reforzaría el lazo (biológico o de sangre) entre ellos. Sin embargo, era creencia común que los niños podían heredar enfermedades, malos hábitos y defectos de carácter de la nodriza a través de su leche. ${ }^{11}$ Esta es una de las razones por la que cuando la relación entre Miña y Clarissa se intensifica, Valeria resiente su presencia. Lo que ocurre después es muy similar a lo que le ocurrió a María de Regla en Cecilia Valdés: Valeria fuerza un abrupto destete y expulsa a Miña de la casa. Sus opciones de trabajo cambian cuando eventualmente regresa, pero continúan siendo un reflejo de su posición social, ya que pasa de ser nodriza a sirvienta y lavandera.

Además del color de piel, el nivel de educación y el derecho al voto distinguen a Miña de las mujeres de la familia a la cual sirve. La nodriza es analfabeta pero -a diferencia de María de Regla- cuestiona esta diferencia y le pide a Clarissa que le enseñe a leer y a escribir. Esto ocurre al regresar de su "exilio" y mientras trabaja como criada y lavandera. En un momento en que las mujeres puertorriqueñas aún no tienen el derecho al voto, ella también protesta contra ésto y logra que Clarissa reconozca al menos parcialmente los derechos de las mujeres de clase trabajadora. ${ }^{12}$ Clarissa le enseña a leer y a escribir y en su cumpleaños Miña le regala un retrato suyo firmado con "Miña Besosa". La foto con el nombre es un intento símbólico de insertase en la historia familiar. Sin embargo, la imagen se mantiene como decoración, ya que no es incluída en el álbum de familia o en los espacios en que se identifican los miembros 'oficiales'.

Cuando Miña empezó a lactar a Clarissa, la salud de la niña mejoró, ganó peso y estableció un lazo afectivo con la nodriza. Miña cargaba la niña amarrada a su cuerpo

11 Valerie Fildes identifica esta creencia como un legado que trajeron los colonizadores: "Despite the then current belief that the wet nurse's characteristics were transmitted to her nursling via her breast milk, it was commonplace for the wealthier white colonists to use both Indians and Negroes to suckle their children" ["A pesar de su creencia actual que las características de la nodriza eran transmitidos al lactante através de la lecha de su pecho, era muy común para los colonizadores blancos más ricos usar tant a las indias como a las negras para la lactancia de sus hijos"] (128; traducción del editor).

12 Clarissa dice que las mujeres con un grado universitario deben tener el derecho de votar. Miña se enoja y le responde que todas las mujeres deben tener este derecho. Más tarde Miña quiere aprender a leer y a escribir y Clarissa le enseña. Miña está consciente de los prejuicios de género en el seno de la familia, critica el trato privilegiado del varón y reúsa colaborar con esto. De todas estas formas ella demuestra que no es completamente pasiva e ignorante de la situación de mujeres como ella en esta sociedad. Expresar su opinión con Clarissa es su único medio para lograr cambios.

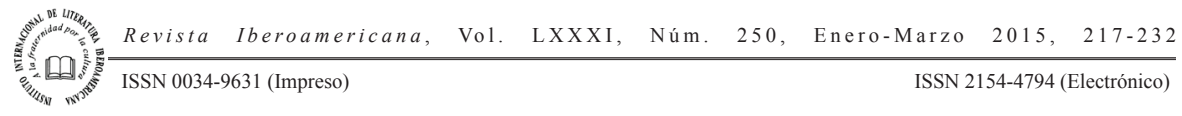


y cubierta de hojas medicinales. Pero su madre prefiere seguir los consejos médicos, señalando que "Hoy, todos los manuales de instrucción afirman que es más saludable dejar que los bebés lloren a cargarlos en brazos. Si se acostumbran al sacrificio de pequeños, sufrirán menos de grandes" (119). ${ }^{13}$ De esta manera Valeria reemplaza al padre por el médico o experto en sicología (representado en los manuales de crianza) como el nuevo recurso de autoridad patriarchal (Thurer).

Ann Laura Stoler señala que la nodriza representa otro tipo de amenaza debido a la diferencia cultural y/o de idioma. Esta diferencia se creía también que podría tener un efecto transmitible a través de la leche y es otra razón por la cual las relaciones a través del contacto corporal provocaban ansiedades raciales y culturales. El peligro residía en la idea de que con exceso de cuidados y atenciones la nodriza podría criar ciudadanos dependientes, malcriados y por consecuencia "defectuosos".

La narración de Ferré ejemplifica el trauma que ocurre cuando se limitan o se terminan abruptamente estos cuidados. Como resultado, se afecta el desarrollo infantil y específicamente el lenguaje. El concepto de "mamar la lengua materna" tiene raíz en la herencia española desde la época colonial, ya que generalmente era la nodriza quien enseñaba al bebé a hablar. ${ }^{14}$ En aquella época se creía que el lenguaje podía ser filtrado en la leche, como señala también Julio Ramos. ${ }^{15}$ Luego de la separación de la nodriza, Clarissa retrocede en su desarrollo infantil, demostrando comportamientos primitivos. Deja de hablar y después de llorar sin parar por 36 horas "se comió todo el potaje con las manos y vació el tazón con la lengua. Cuando teminó, se hizo caca y pis sobre el piso como si fuera un animalito" (119). Ya que el lenguaje y la socialización lo aprendía de la nodriza, al perder la conexión física se obstaculiza su desarrollo. Valeria y Álvaro observan el efecto nocivo del destete en su hija y deciden que Miña puede regresar, pero

${ }^{13}$ La preferencia de Valeria por libros y manuales para la crianza es parte de las luchas de poder entre estas mujeres. Como Miña no sabe leer, ésta es una manera de imponerle un conocimiento distinto al que ella favorece. El modo de crianza de Miña se basa en la proximidad física (quizás lo que hoy dia se conoce como la teoría de "Attachment Parenting" divulgada por Dr. Bill Sears) y el uso de medicinas naturales como las plantas.

${ }^{14}$ Para estudios sobre las nodrizas en la literatura española ver los ensayos de Emilie L. Bergman: "Language and 'Mother's Milk': Maternal Roles and the Nurturing Body in Early Modern Spanish Texts" in Maternal Measures: Figuring Caregiving (2000) y "Milking the Poor: Wet-Nursing and the Sexual Economy of Early Modern Spain" en Marriage and Sexuality in Medieval and Early Modern Iberia. (2002). En el segundo ensayo Bergman menciona varios factores que resultan similares a la narración de Ferré en Vecindarios Excéntricos. La escasez de estudios en torno a las nodrizas, la ambiguedad hacia las relaciones interraciales en la lactancia y la idea de que se podían pasar en la leche atributos personales, enfermedades y hasta la moral coinciden con el caso puertorriqueño. El modelo de "leche como sangre" era prevalente en España y se transportó a Puerto Rico a través de la colonización.

15 De acuerdo a esta lectura podríamos entonces analizar el comportamiento de Dolores en Cecilia Valdés como también reflejo de un destete temprano y abrupto. Es quizás por esta ausencia que la hija de María de Regla se mantiene cerca de las hijas de la familia blanca, en búsqueda del afecto y el calor que se limitó en su niñez.

Revista Iberoamericana, Vol. LXXXI, Núm. 250, Enero-Marzo 2015, 217-232 ISSN 0034-9631 (Impreso)

ISSN 2154-4794 (Electrónico) 
con límites bien definidos: "Le dieron órdenes de que bajo ningún concepto se acercara a la muchachita, so pena de perder su empleo" (Ferré 120). Valeria reubica a Miña en el rol de lavandera, sin saber que este nuevo rol le da acceso a los secretos de la familia:

Estoy segura de que por eso sabía tantos de nuestros secretos: porque estaba a cargo de nuestra ropa interior. Siempre adivinaba cuando había un niño en camino porque sabía si abuelo Álvaro y abuela Valeria habían hecho el amor. También sabía cuando no lo hacían y las cosas entre ellos andaban tensas. No se le hacía dificil adivinar cuando había huelga en la central porque abuelo Álvaro en seguida amanecía con diarrea. Se enteró antes que Valeria cuando mis tías se hicieron señoritas y cuando Alejandro empezó a soñar con mujeres, porque en la mañana se despertaba con el pajama todo pegajoso de semen y parecía que le había caído encima un chubasco (Ferré 127).

Miña guardaba una bola hecha de pedazos de jabones que usaba la familia y conservaba los olores de todos sus miembros. Esta bola funciona como la leche, manteniendo un hilo conector entre los hermanos y se extiende a otros miembros de la familia. ${ }^{16}$ Elvira encuentra la bola de jabón; o sea, que descubre el "secreto" de Miña y mantiene esta información, convirtiéndose en cómplice de la nodriza. ${ }^{17}$

Frances Aparicio (2003) ha analizado las implicaciones clasistas evidentes en la escena final de Vecindarios Excéntricos. ${ }^{18}$ La narración termina con el sueño recurrente de Elvira, en el que muchas de las mujeres de su familia son arrastradas por un río mientras ella observa desde el interior de un carro junto a su madre. Clarissa saca un

16 Elvira reconoce que Miña mantiene la familia unida: "Y sobre todos los perfumes reinaba el olor de Miña, que mantenía unidos todos aquellos fragmentos" (127). Miña conoce los secretos de familia porque tiene acceso a los olores de las secreciones corporales, como el sudor, la mestruación y el semen. La leche, como otra secreción corporal, funciona igualmente para mantener la unión.

17 Patricia Hill Collins (1994) urge a los lectores a contextualizar al analizar ejemplos de madres como Miña. También insiste en esta misma estrategia de colocar la madre en el centro para cuestionar análisis feministas de la maternidad. Así, en Vecindarios Excéntricos las necesidades de la madre, nodriza y sus hijos se ponen en segundo lugar para privilegiar a la otra familia. Sus sentimientos, sus sacrificios y las condiciones en las que debe vivir su familia no son considerados ni siquiera por Urbano. Sólo hay un espacio parcial para voz y la situación personal de Miña: "Miña empezó a llorar y siguió así toda la noche. Se le rompía el. corazón nada más que de pensar que tendría que dejar al bebé con su hermana para que lo cuidara" (117).

'8 Frances Aparicio describe la perspectiva clasista que informa los escritos de Rosario Ferré en "Writing Migrations: The Place(s) of U.S. Puerto Rican Literature”. Aparicio afirma que la perspectiva dominante en esta narración es la de una clase social privilegiada con sujetos que son incapaces o se niegan a identificarse y/o incluir las luchas de otros sectores poblacionales, como los inmigrantes. Esta perspectiva explica también la exclusión de sujetos como Miña o el ofrecimiento de un espacio supervisado, limitado y condicional. Según Aparicio, la disposición de Ferré al escribir en inglés y autodesignarse escritora "latina" intenta reafirmar su agenda política, que entre otras consideraciones favorece la integración de Puerto Rico a los Estados Unidos.

Revista Iberoamericana, Vol. LXXXI, Núm. 250, Enero-Marzo 2015, 217-232 ISSN 0034-9631 (Impreso)

ISSN 2154-4794 (Electrónico) 
dólar por la ventana, lo que Aparicio interpreta como "the closing of class boundaries necessary for the protection of their economic and social privilege" ["la cercanía de los límites de clases necesarios para la protección de los privilegios económicos y sociales"] (159; traducción del editor).

Clarissa y yo, vestidas con nuestra ropa de domingo, permanecimos perfectamente quietas dentro del Pontiac, sin pronunciar una sola palabra. Entonces mamá sacó un dólar de su bolso, bajó el cristal una pulgada, e hizo ondear el billete fuera de la ventana hasta que los campesinos que aguardaban en la ribera opuesta nos vieron, y acudieron con sus bueyes a sacarnos. (448)

Miña no aparece en esta escena, en la cual se nombran a otras mujeres de la familia como abuelas, y tías, ni en el árbol genealógico al principio del texto, lo cual-además de la diferencia de clase que argumenta Aparicio-marca el privilegio del modelo biológico y/o de sangre. La inclusión (parcial) de Miña se da a través de la leche y se ubica en la relación entre madre e hija, donde logra introducir algunas ideas de cambios sociales. En la casa ella introduce elementos como la cotorra, Felicia ${ }^{19}$ que proporcionan un aire exótico al personaje. En ocasiones Miña lleva un sarape mexicano, que evoca el chal que cubre y ata los cuerpos de la nodriza y la bebé durante la lactancia. No obstante, este elemento también diluye su identidad cultural puertorriqueña, taína y africana. Aunque la relaciona con accesorios femeninos latinoamericanos, a su vez la encasilla en las labores femeninas y de la maternidad. Más tarde, Clarissa lleva el sarape mientras delibera con Miña antes de su boda y durante sus estudios universitarios, cuando "se pasaba las noches estudiando en la biblioteca, envuelta en el sarape mexicano de Miña" (147). ${ }^{20}$ Antes de su muerte y durante su enfermedad, su hija Elvira, cubre los pies de Clarissa para protegerla del frío con "el viejo sarape de lana color arcoiris que Miña le había regalado" (438). Es decir que la labor de Miña sigue siendo en ciertos momentos la de soporte afectivo para las mujeres a las que sirve. En esos momentos su inclusión se limita al aspecto simbólico a través de elementos que aunque representan una aportación cultural y afectiva, la circunscriben a aspectos tradicionales y manipulados por la clase privilegiada.

En Cecilia Valdés y en Vecindarios excéntricos las nodrizas se mantienen en posiciones de servicio y con obvias limitaciones. Sin embargo las diferencias en la situación de cada una en su contexto histórico son resultado de evoluciones sociales feministas de la cultura caribeña del siglo xx. Mientras que en la novela de Villaverde

19 Además de Felicia, la cotorra de Miña, su descripción física incluye alusiones a la naturaleza como "parecía que estuviera hecha de madera" (126) y "tenía una mirada de águila posada sobre los pómulos altos" (126).

${ }^{20}$ Clarissa se envuelve también en el sarape mexicano cuando hace la labor de intermediaria y consejera de una de sus hermanas, Siglinda.

Revista Iberoamericana, Vol. LXXXI, Núm. 250, Enero-Marzo 2015, 217-232 ISSN 0034-9631 (Impreso)

ISSN 2154-4794 (Electrónico) 
María de Regla es expulsada del espacio familiar, en la de Ferré Miña regresa, vive en la casa y puede alzar su voz a favor de mejores oportunidades de educación, el derecho al voto femenino y contra las actitudes machistas en la sociedad puertorriqueña. A pesar de que la ansiedad cultural y racial que describen Stoler y Ramos aún sigue vigente en la sociedad puertorriqueña del siglo xx, el regreso a la casa señala una limitada y relativa apertura para las voces subalternas que no existe en la sociedad esclavista cubana del siglo XIX.

Ambas nodrizas apoyan la mezcla racial y la conexión entre miembros de la familia y son receptáculos de secretos familiares. Miña es el eje (semi-invisible) que mantiene la unión familiar. Valeria y Álvaro se dan cuenta del daño que la pérdida de la nodriza tiene en la niña ya que esta generación se verá limitada en su desarrollo social por no mantener un lazo con sus orígenes; lo que sucede con Clarissa. La resultante dificultad para establecer lazos afectivos se interpone especialmente en la relación entre la madre y la hija pero se extiende a otras relaciones afectivas. Elvira sentía que Clarissa tenía "una astilla de hielo" en el corazón y "se le hacía muy difícil querer a la gente" (Ferré 122). Sin embargo, en Cecilia Valdés es María quien identifica este sentimiento en sí misma durante su exilio al señalar: "ya no podía querer; no me salía de adentro el querer a nadie [...] mi corazón se había secado" (Villaverde 394). Para intentar evitar que se perpetúe este legado, antes de la boda de Clarissa y Aurelio, Miña interviene para ayudar a su hija de leche, quien tenía dudas de casarse. ${ }^{21}$ Como resultado, "pronto la astilla de hielo que llevaba en el corazón empezó a derretirse" (182); es decir, que Clarissa puede comenzar a amar en este momento en parte gracias a la intervención de Miña. Sin embargo la "astilla" -o el distanciamiento afectivo- se mantiene entre Clarissa y Elvira, lo cual sugiere que los conflictos raciales y clasistas se heredan de generación en generación por vía materno filial.

Miña y Clarissa tienen más oportunidades que María de Regla y Adela de conversary compartir en momentos significativos como antes de la boda y del ingreso a la universidad. En este contexto y como mujer de clase alta de mediados de siglo xx, Clarissa tiene también la oportunidad de estudiar y de votar. Miña le concientiza de que esos mismos derechos deben ser compartidos con todas las mujeres, incluso las de clase baja. Es decir, que el derecho a una educación y el sufragio femenino - dos importantes logros feministas del siglo xx-se discuten entre nodriza e hija de leche. Aún así, se mantiene la ambigüedad racial y de clase en el contexto social ya que en el espacio del hogar Miña sigue en un lugar marginal.

${ }^{21}$ Miña habla secretamente con Aurelio y le cuenta el episodio del destete abrupto de Clarissa y sus consecuencias. Esta intervención tiene el objetivo de ayudar al novio a entender las dudas y la frialdad de la novia. Tal parece que la única manera de derretir la supuesta astilla de hielo de Clarissa es con el matrimonio dentro de su misma clase social, como sucede en este caso.

Revista Iberoamericana, Vol. LXXXI, Núm. 250, Enero-Marzo 2015, 217-232 ISSN 0034-9631 (Impreso)

ISSN 2154-4794 (Electrónico) 
Tanto en la novela de Villaverde como en la de Ferré el trabajo de las nodrizas sostiene a miembros de la clase alta y de la clase trabajadora. Sin embargo, las relaciones personales resultantes en el ejemplo puertorriqueño marcan una diferencia con el ejemplo cubano a pesar de que la presencia del cuerpo negro o mestizo produce tensiones similares. Estas tensiones son especialmente evidentes entre las mujeres. Las diferencias de raza y clase además de la competencia por los favores y respaldo masculinos impiden una verdadera solidaridad entre ellas. Las necesidades básicas como el acceso a una casa o albergue y medios de sustento para sus familias todavía dependen en gran medida del apoyo económico masculino aún para la generación de Clarissa en la novela de Ferré.

Miña -la nodriza del siglo xx- obtiene privilegios de los cuales María de Regla carecerá un siglo antes, pero continúa con severas limitaciones. Si como señala Gladys Feijoo, al final de Cecilia Valdés la inclusión de los esclavos y/o mulatos pobres como parte de la configuración del imaginario nacional queda en manos de la generación mulata y criolla que está apenas naciendo, en Vecindarios excéntricos este proyecto avanza un poco más pero falla en la inclusión completa. ${ }^{22}$ No es Clarissa sino su hija Elvira quien tiene la voz narrativa, cuenta la historia familiar y disfruta de libertades que otras mujeres anteriormente no tuvieron, como más oportunidades de educación, el derecho a divorciarse y de vivir independientemente. Elvira incluso manipula su historia personal y su lugar en la familia simbólicamente cuando construye su propio álbum de recuerdos de la infancia, el que su madre había ignorado por privilegiar al varón, y señala: "fue la primera vez que me di a luz a mí misma" (317). A pesar de este poder creativo, Elvira hereda las ambigüedades resultantes de una historia familiar y nacional que incluye la diversidad y simultáneamente los legados de la esclavitud, la colonización y el machismo. Por eso olvida incluir a Miña en su álbum y en el sueño final y se inclina a mantener la estructura básica familiar/nacional que ya había sido establecida. No obstante, entre Clarissa y Elvira la leche de la nodriza deja un legado que produce tanto divisiones y tensiones como elementos conectores. La leche en el siglo XIX encarna la narrativa silenciada de la esclava, la mezcla racial y los secretos de familia. En el siglo xx la leche mantiene esas significaciones y además permite que la mujer de clase baja introduzca elementos culturales y sociales en el espacio doméstico privilegiado. La narrativa del sujeto subalterno representada en la leche ya no requiere el contacto de sangre (como la mediación de Dolores en Cecilia Valdés) para mantenerse ubicada en los bordes del espacio familiar, pero sí requiere de otro personaje femenino que comparta sus secretos.

En la novela de Villaverde, luego de regresar de su exilio en el campo, María de Regla cuenta su secreto a las mujeres que escuchan su historia, destruyendo así la imagen

22 Gladys Feijoo señala que en Cecilia Valdés "la construcción de la patria nueva queda en el relato como tarea de las futuras generaciones" (19) y que esto ocurrirá "a partir del reconocimeinto y validación de los orígenes mestizos" (21).

Revista Iberoamericana, Vol. LXXXI, Núm. 250, Enero-Marzo 2015, 217-232 ISSN 0034-9631 (Impreso)

ISSN 2154-4794 (Electrónico) 
oficial que se había mantenido de la familia y la nación cubana. En la de Ferré, Miña guarda sus secretos y mantiene su posición ambigüa en la familia. Estos secretos quizás conllevan consecuencias menos graves que la infidelidad, el incesto y la mezcla racial en el siglo XIX. Aunque la presencia de ambas nodrizas expone los conflictos inherentes a la fantasía nacional, la nodriza puertorriqueña también contruye puentes funcionando como hilo conector entre algunos personajes. El propósito de Miña no es desarticular completamente el modelo racial nacional porque éste ya incluye la mezcla en el mito fundacional. Sin embargo, logra evidenciar que este modelo es cuestionable y carece de una presencia femenina. La ubicación ambigüa de Miña expone la actitud contradictoria que existe en sectores puertorriqueños hacia la negritud, la herencia africana y de otros grupos sociales. Su labor más urgente consiste en provocar el cuestionamiento de una perspectiva clasista entre las mujeres. Por eso es significativo su regreso a la casa, simbolizando el intento de inserción de la clase trabajadora y la mujer de distinta categoría racial, además de darle una voz en asuntos relacionados con la educación y el derecho al voto. En estos ejemplos de narrativa caribeña, las nodrizas y su leche ocupan una posición marginal en el imaginario nacional. Sin embargo, desde ese espacio limitado ellas colaboran en la formación y cuestionamiento de la identidad nacional a pesar de la resistencia que enfrentan en espacios caribeños a través de los siglos.

\section{FuENTES CITADAS}

Aedo, María Teresa. "Cecilia Valdés: Diosas, vírgenes y madres en la identidad mestiza de Cuba". Acta Literaria 20 (1995): 5-22.

Arroyo, Jossiana. Travestismos culturales: literatura y etnografia en Cuba y Brasil. Pittsburgh: Instituto Internacional de Literatura Iberoamericana, 2003.

Aparicio, Frances. "Writing Migrations: The Places(s) of U.S. Puerto Rican Literature." Beyond the Borders: American Literature and Post-colonial Theory. Deborah Madsen, ed. London: Pluto, 2003. 207-231.

Bergmann, Emilie L. "Language and 'Mother's Milk': Maternal Roles and the Nurturing Body in Early Modern Spanish Texts." Maternal Measures: Figuring Caregiving in the Early Modern Period. Naomi J. Miller and Naomi Yavneh, eds. Aldershot: Ashgate, 2000.

"Milking the Poor: Wet-Nursing and the Sexual Economy of Early Modern Spain." Marriage and Sexuality in Medieval and Early Modern Iberia. Eukene Lacarra Lanz, ed. New York: Routledge, 2002.

Caballero María. Ficciones isleñas: Estudios sobre la literatura de Puerto Rico. San Juan: Editorial de la UPR, 1999.

Duany, Jorge. The Puerto Rican Nation on the Move: Identities on the Island and in the United States. Chapel Hill: U of North Carolina P, 2002.

Ferré, Rosario. Vecindarios excéntricos. New York: Vintage, 1998.

Revista Iberoamericana, Vol. LXXXI, Núm. 250, Enero-Marzo 2015, 217-232 ISSN 0034-9631 (Impreso) ISSN 2154-4794 (Electrónico) 
Feijoo, Gladys. "La madre en la novela Cecilia Valdés de Cirilo Villaverde". Círculo; publicación del círculo de Cultura Panamericano 15 (1986): 79-84.

Fildes, Valerie. "Wet Nursing in Colonial America." Wet Nursing: A History from Antiquity to the Present. New York: Blackwell, 1988. 127-143.

Gelpí, Juan G. Literatura y paternalismo en Puerto Rico. 2nd ed. San Juan: Editorial de la UPR, 2005.

Handley, George B. Postslavery Literatures in the Americas: Family Portraits in Black and White. Charlottesville: UP of Virginia, 2000.

Hill Collins, Patricia. "The Meaning of Motherhood in Black Culture and Black MotherDaughter Relationships." Double Stitch: Black Women Write about Mothers and Daughters. Patricia Bell-Scott, et al. Boston: Beacon Press, 1991. 42-60.

Knibiehler, Yvonne. "Madres y nodrizas" Figuras de la madre. Silvia Tubert, ed. Madrid: Cátedra, 1996. 95-118.

Martínez-San Miguel, Yolanda. "Deconstructing Puerto Ricanness through Sexuality: Female Counternarratives on Puerto Rican Identity (1894-1934)." Puerto Rican Jam: Rethinking Colonialism and Nationalism. Ramón Grosfoguel and Frances Negrón-Muntaner, eds. Minneapolis: Minnessota UP, 1997. 127-139.

Moreno, Marisel C. Family Matters: Puerto Rican Women Authors on the Island and the Mainland. Charlottesville: U of Virginia P, 2012.

Ramos, Julio. Paradojas de la letra. Caracas: Ediciones eXcultura, 1996.

Rich, Adrienne. Of Woman Born: Motherhood as experience and institution. New York: Norton, 1986.

Robinson, Amy. "Illegitimacy, Incest and Insanity: An Analysis of Secrecy in Cecilia Valdés (Cuba, 1882) and Carmen (Mexico, 1882)." Leading Ladies: Mujeres en la literatura hispana y en las artes. Yvonne Fuentes and Margaret Parker, eds. Louisina: Louisiana UP, 2006. 49-59.

Suárez Findlay, Eileen J. Imposing Decency: The Politics of Sexuality and Race in Puerto Rico, 1870-1920. Durham: Duke UP, 1999.

Stoler, Ann Laura. Carnal Knowledge and Imperial Power: Race and the Intimate in Colonial Rule. California: U of California P, 2002.

Race and the Education of Desire: Foucault's History of Sexuality and the Colonial Order of things. $5^{\text {th }}$ ed. Durham: Duke UP, 2000.

Thurer, Shari. The Myths of Motherhood: How Culture Reinvents the GoodMother. New York: Houghton Mifflin, 1994.

Kutzinski, Vera M. Sugar's Secrets: Race and the Erotics of Cuban Nationalism. USA: UP of Virginia, 1993.

Villaverde, Cirilo. Cecilia Valdés. La Habana: Editorial Letras Cubanas, 2002.

Williams, Lorna. "The Representation of the Female Slave in Villaverde's Cecilia Valdés." Hispanic Journal 14/1 (1993): 73-89.

Revista Iberoamericana, Vol. LXXXI, Núm. 250, Enero-Marzo 2015, 217-232 ISSN 0034-9631 (Impreso)

ISSN 2154-4794 (Electrónico) 
"From Dusky Venus to Mater Dolorosa: The Female Protagonist in the Cuban Antislavery Novel." Woman as Myth and Metaphor in Latin American Literature. Naomi Lindstrom y Carmelo Virgilio, eds. Columbia: U of Missouri P, 1986. Yalom, Marilyn. A History of the Breast. New York: Knopf, 1997. 